\title{
Measurement Comparability of Electronic and Paper Administration of Visual Analogue Scales: A Review of Published Studies
}

\author{
Bill Byrom ${ }^{1}$. $\cdot$ Celeste A. Elash ${ }^{2}$. Sonya Eremenco ${ }^{3} \cdot$ Serge Bodart $^{4} \cdot$ Willie Muehlhausen $^{5} \cdot$ Jill V. Platko $^{6}$. \\ Chris Watson ${ }^{7} \cdot$ Cindy Howry ${ }^{8}$
}

Received: 13 July 2021 / Accepted: 20 January 2022 / Published online: 10 February 2022

(c) The Author(s) 2022

\begin{abstract}
Background Visual analogue scales (VASs) are used in a variety of patient-, observer- and clinician-reported outcome measures. While typically included in measures originally developed for pen-and-paper completion, a greater number of clinical trials currently use electronic approaches to their collection. This leads researchers to question whether the measurement properties of the scale have been conserved during the migration to an electronic format, particularly because electronic formats often use a different scale length than the $100 \mathrm{~mm}$ paper standard.

Methods We performed a review of published studies investigating the measurement comparability of paper and electronic formats of the VAS.

Results Our literature search yielded 26 studies published between 1997 and 2018 that reported comparison of paper and electronic formats using the VAS. After excluding 2 publications, 23 of the remaining 24 studies included in this review reported electronic formats of the VAS (eVAS) and paper formats (pVAS) to be equivalent. A further study concluded that eVAS and pVAS were both acceptable but should not be interchanged. eVAS length varied from 21 to $200 \mathrm{~mm}$, indicating that $100 \mathrm{~mm}$ length is not a requirement.

Conclusions The literature supports the hypothesis that eVAS and pVAS provide comparable results regardless of the VAS length. When implementing a VAS on a screen-based electronic mode, we recommend following industry best practices for faithful migration to minimise the likelihood of non-comparability with pVAS.
\end{abstract}

Keywords Electronic patient-reported outcome $\cdot$ ePRO $\cdot$ Measurement comparability $\cdot$ Measurement equivalence $\cdot$ Visual analogue scale $\cdot$ VAS

\section{Abbreviations \\ BASDAI Bath Ankylosing Spondylitis Disease Activity Index (Table 1) \\ eVAS Visual analogue scale presented electronically}

Bill Byrom

bill.byrom@signanthealth.com

1 Signant Health, Ground Floor, Waterfront Embankment, Manbre Road, Hammersmith, London W6 9RH, UK

2 YPrime, Malvern, PA, USA

Critical Path Institute, Tucson, AZ, USA

IDDI, Ottignies, Belgium

Safira Clinical Research Ltd, Nenagh, Ireland

6 Signant Health, Blue Bell, PA, USA

7 THREAD, Cary, NC, USA

8 assisTek, Doylestown, PA, USA
FDA US Food and Drug Administration

FP Feature phone (Table 1)

HAQ-DI Health Assessment Questionnaire Disability Index (Table 1)

LCSS Lung Cancer Symptom Scale (Table 1)

NRS Numeric rating scale

PC Personal computer (Table 1)

PDA Personal digital assistant (Table 1)

PROM Patient-reported outcome measure

pVAS Visual analogue scale presented on paper

SF-MPQ Short form McGill Pain Questionnaire

(Table 1)

SP Smartphone (Table 1)

VAS Visual analogue scale

WOMAC Western Ontario and McMaster Universities Osteoarthritis Index 


\section{Introduction}

Visual analogue scales (VASs) are commonly used in the assessment of a variety of health-related constructs including pain [1-3], mood [4], quality of life [5, 6], and patient satisfaction [7], and have been found to provide reliable and valid data [8]. The VAS is defined in the FDA's Guidance for Industry on Patient-Reported Outcome Measures [9] as "a line of fixed length (usually $100 \mathrm{~mm}$ ) with words that anchor the scale at the extreme ends and no words describing intermediate positions" (Fig. 1). VASs are brief and simple to complete and are particularly useful when assessing a single construct with many perceptible gradations due to the continuous nature of the scale and the 101 possible response options. These characteristics also contribute to the scale's high sensitivity to change [10].

\section{VAS Acceptability and Utility}

Because the VAS uses few words, the vocabulary level of the respondent is generally not a concern, provided the anchor descriptors are straightforward, common terms [11]. However, some research has demonstrated poor reliability of the VAS in illiterate patients [12].

People with visual impairments can typically see a VAS easily. Most respondents have sufficient dexterity to use a VAS [11], although those with dexterity issues, for example due to arthritis or orthopaedic trauma to their hands or arms, may have difficulty targeting a very specific point on the scale to indicate their desired response [10].

Some research indicates children younger than 6 or 7 may have difficulty responding to a VAS [13]. In addition, older adults may have more difficulty responding to a VAS than younger people [10], with some research showing increased age associated with incorrect response on a paper VAS [14].

The VAS has additional limitations related to the visual nature of the scale. For example, a VAS is not appropriate for telephone interview-based or interactive voice response (IVR) system- or voice assistant-based data collection because the respondent must be able to see the scale in order to select a response.

\section{Implementation Formats}

Traditionally, the VAS has been implemented on paper (pVAS) with a $100 \mathrm{~mm}(10 \mathrm{~cm})$ line to facilitate measurement of 101 discrete points ( 0 to 100 ) with a metric ruler [15]. This implementation can introduce sources of error. Measurement of the score on paper with a metric ruler may introduce human error [11] and additional scoring error may be introduced if the response is ambiguous, i.e. not a clear mark within the confines of the scale anchors [8]. Additionally, photocopying the pVAS can change the length of the line, making the comparison between distances measured on the original and the photocopied version difficult $[10,14]$.

These limitations of the pVAS can be mitigated by implementation on a screen-based electronic platform (Fig. 1). An electronic VAS (eVAS) can be implemented on a line of any length, provided the response fields allow for selection of precisely 101 discrete points comprising an equal number of pixels on the line. With an eVAS, the pixels along the VAS line are invisibly categorised into 101 equal regions so that the position of the response can be converted into a numeric score from 0 to 100 . This approach prevents ambiguous or invalid responses and eliminates the need for manual measurement with a ruler, hence removing that source of human error.
Fig. 1 Typical representations of pVAS and eVAS based on The Stanford Health Assessment Questionnaire Disability Index HAQ-DI [46]

\section{(a) pVAS}

How much pain have you had because of your illness IN THE PAST WEEK: PLACE A VERTICAL (|) MARK ON THE LINE TO INDICATE THE SEVERITY OF THE PAIN

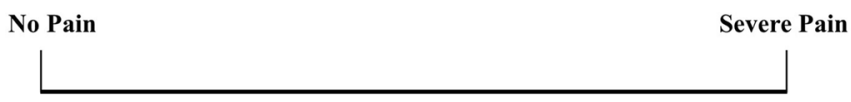

(b) eVAs

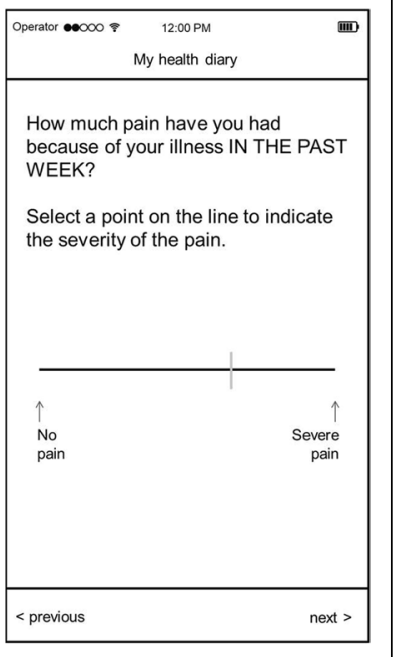


Table 1 Summary of articles reviewed

\begin{tabular}{|c|c|c|c|c|c|c|c|c|}
\hline Refs. & $\mathrm{n}$ & Population & Age & pVAS & eVAS & Electronic mode & PROM & $\begin{array}{l}\text { Association } \\
\text { measured }\end{array}$ \\
\hline [1] & 30 & $\begin{array}{c}\text { Rheumatoid } \\
\text { arthritis }\end{array}$ & Range: 49-70 & $100 \mathrm{~mm}$ & NR & PDA & $\begin{array}{l}\text { Pain, fatigue, } \\
\text { global health }\end{array}$ & $r=0.86-0.93$ \\
\hline [2] & 38 & $\begin{array}{c}\text { Rheumatoid } \\
\text { arthritis }\end{array}$ & $\begin{array}{l}\text { Mean: } 58 \\
\quad[S D=13]\end{array}$ & $100 \mathrm{~mm}$ & NR & PDA & $\begin{array}{l}\text { Pain, fatigue, } \\
\text { global health }\end{array}$ & NR \\
\hline$[3]$ & 155 & Chronic pain & Range: 19-69 & $100 \mathrm{~mm}$ & $40-80 \mathrm{~mm}$ & SP, Tablet & Pain & $\mathrm{ICC}=0.94$ \\
\hline [4] & 71 & $\begin{array}{l}\text { Panic disorder } \\
\text { and healthy }\end{array}$ & Range: $17-72$ & $100 \mathrm{~mm}$ & $200 \mathrm{~mm}$ & $\mathrm{PC}$ & Anxiety & $\rho=0.98$ \\
\hline$[23]$ & 200 & Chronic pain & $\begin{array}{l}\text { Mean: } 56.5 \\
{[S D=14]}\end{array}$ & $100 \mathrm{~mm}$ & $50 \mathrm{~mm}(\mathrm{EST})$ & PDA & Pain & NR \\
\hline [44] & 28 & Haemodialysis & $\begin{array}{l}\text { Mean: } 61 \\
\quad[S D=17]\end{array}$ & $100 \mathrm{~mm}$ & $100 \mathrm{~mm}$ & $\mathrm{PC}$ & Appetite & $r=0.572-0.770$ \\
\hline [26] & 35 & $\begin{array}{l}\text { General popula- } \\
\text { tion }\end{array}$ & Range: 22-62 & $100 \mathrm{~mm}$ & $40 \mathrm{~mm}$ & FP & NR & NR \\
\hline$[35]$ & 12 & $\begin{array}{l}\text { General popula- } \\
\text { tion }\end{array}$ & Range: 8-10 & $100 \mathrm{~mm}$ & $24 \mathrm{~mm}$ & SW & Appetite & $r=0.65-0.75$ \\
\hline [36] & 12 & $\begin{array}{l}\text { General popula- } \\
\text { tion }\end{array}$ & $\begin{array}{l}\text { Mean: } 30 \\
\quad[S D=12]\end{array}$ & $100 \mathrm{~mm}$ & $66 \mathrm{~mm}$ & PDA & Appetite & NR \\
\hline [37] & 65 & $\begin{array}{l}\text { General popula- } \\
\text { tion }\end{array}$ & Range: 19-54 & $100 \mathrm{~mm}$ & $21 \mathrm{~mm}$ & $\mathrm{FP}$ & Alcohol effects & $\mathrm{ICC}=0.96$ \\
\hline [27] & 30 & $\begin{array}{l}\text { General popula- } \\
\text { tion }\end{array}$ & $\begin{array}{l}\text { Medians: } 34 \\
\text { (M), } 31(\mathrm{~F})\end{array}$ & $100 \mathrm{~mm}$ & $70 \mathrm{~mm}$ & PDA & Appetite & NR \\
\hline$[28]$ & 22 & $\begin{array}{l}\text { General popula- } \\
\text { tion }\end{array}$ & Range: 56-86 & $100 \mathrm{~mm}$ & $100 \mathrm{~mm}$ & Tablet & Pain & $R^{2}=0.9998$ \\
\hline [29] & 24 & $\begin{array}{l}\text { General popula- } \\
\text { tion }\end{array}$ & Range $19-57$ & $100 \mathrm{~mm}$ & $50 \mathrm{~mm}$ & PDA & NR & $R^{2}=0.997-0.999$ \\
\hline$[30]$ & 88 & $\begin{array}{l}\text { Rheumatoid } \\
\text { arthritis, } \\
\text { ankylosing } \\
\text { spondylitis } \\
\text { and psoriatic } \\
\text { arthritis }\end{array}$ & $\begin{array}{l}\text { Mean: } 54 \\
\quad[\mathrm{SD}=11]\end{array}$ & NR & NR & $\mathrm{PC}$ & Pain & $\begin{array}{c}\mathrm{ICC}=0.867- \\
0.943\end{array}$ \\
\hline$[31]$ & 189 & Chronic pain & Range: $18-82$ & NR & NR & $\mathrm{PC}$ & $\begin{array}{l}\text { SF-MPQ (pain } \\
\text { intensity) }\end{array}$ & $\rho=0.68$ \\
\hline$[32]$ & 86 & $\begin{array}{l}\text { Non-small cell } \\
\text { lung cancer }\end{array}$ & NR & $100 \mathrm{~mm}$ & $53 \mathrm{~mm}$ & PDA & LCSS & $\begin{array}{l}\mathrm{ICC}=0.645- \\
0.893 \\
r=0.651-0.847\end{array}$ \\
\hline$[33]$ & 355 & NR & NR & NR & 50-800 pixels & $\mathrm{PC}$ & NR & NR \\
\hline [34] & 104 & $\begin{array}{l}\text { Multiple sclero- } \\
\text { sis and general } \\
\text { population }\end{array}$ & $\begin{array}{l}\text { Mean: } 49 \\
{[\mathrm{SD}=9]}\end{array}$ & $100 \mathrm{~mm}$ & $100,200 \mathrm{~mm}$ & SP, Tablet & NR & NR \\
\hline$[38]$ & 20 & $\begin{array}{l}\text { General popula- } \\
\text { tion }\end{array}$ & $\begin{array}{l}\text { Means: M: } 37 \\
\quad[S D=13] \\
F: 32[S D=9]\end{array}$ & $100 \mathrm{~mm}$ & $52 \mathrm{~mm}$ & PDA & Appetite & $R^{2}=0.671-0.868$ \\
\hline [39] & 30 & $\begin{array}{l}\text { Osteoarthritis } \\
\text { (knee) }\end{array}$ & Range: 46-77 & $100 \mathrm{~mm}$ & NR & $\mathrm{PC}$ & WOMAC v3 & ICC: $0.87-0.95$ \\
\hline \multirow[t]{2}{*}{ [40] } & 59 & $\begin{array}{l}\text { Rheumatoid } \\
\text { arthritis (RA) }\end{array}$ & $\begin{array}{l}\text { Range (RA): } \\
\text { 26-86 }\end{array}$ & $100 \mathrm{~mm}$ & $200 \mathrm{~mm}$ & $\mathrm{PC}$ & $\begin{array}{l}\text { RA: Pain, } \\
\text { fatigue, global } \\
\text { health }\end{array}$ & $\begin{array}{l}\text { RA: ICC: } \\
0.955-0.972 \\
\rho=0.963-0.973\end{array}$ \\
\hline & 52 & $\begin{array}{l}\text { Ankylosing } \\
\text { spondylitis } \\
\text { (AS) }\end{array}$ & $\begin{array}{l}\text { Range (AS): } \\
21-86\end{array}$ & & & & $\begin{array}{l}\text { AS: pain, } \\
\text { fatigue, BAS- } \\
\text { DAI }\end{array}$ & $\begin{array}{l}\text { AS: ICC: } \\
0.922-0.960 \\
\rho=0.919-0.970\end{array}$ \\
\hline [41] & 43 & $\begin{array}{l}\text { Rheumatoid } \\
\text { arthritis }\end{array}$ & Range: $32-83$ & $100 \mathrm{~mm}$ & $40 \mathrm{~mm}$ & PDA & $\begin{array}{l}\text { SF-MPQ, pain, } \\
\text { fatigue, global } \\
\text { health, HAQ- } \\
\text { DI }\end{array}$ & ICC: $0.77-0.93$ \\
\hline
\end{tabular}


Table 1 (continued)

\begin{tabular}{|c|c|c|c|c|c|c|c|c|}
\hline Refs. & $\mathrm{n}$ & Population & Age & pVAS & eVAS & Electronic mode & PROM & $\begin{array}{l}\text { Association } \\
\text { measured }\end{array}$ \\
\hline [42] & 45 & $\begin{array}{c}\text { Rheumatoid } \\
\text { arthritis }\end{array}$ & Range: $25-83$ & NR & NR & $\mathrm{PC}$ & $\begin{array}{l}\text { Pain, fatigue, } \\
\text { global health }\end{array}$ & ICC: $0.63-0.857$ \\
\hline [43] & 43 & $\begin{array}{l}\text { Rheumatoid } \\
\text { arthritis }\end{array}$ & Range: $18-75+$ & $100 \mathrm{~mm}$ & NR & $\mathrm{PC}$ & $\begin{array}{l}\text { Pain, fatigue, } \\
\text { global health }\end{array}$ & ICC: $0.833-0.941$ \\
\hline
\end{tabular}

$N R$ not reported, EST estimated length from image of device in publication, $F P$ feature phone, $P R O M$ patient-reported outcome measure, $P C$ personal computer, $P D A$ = personal digital assistant, $S P$ smartphone, $S W$ SmartWatch, SF-MPQ Short form McGill Pain Questionnaire, LCSS Lung Cancer Symptom Scale, WOMAC Western Ontario and McMaster Universities Osteoarthritis Index, BASDAI Bath Ankylosing Spondylitis Disease Activity Index, $H A Q-D I$ Health Assessment Questionnaire Disability Index

\section{Migrating from Paper to Electronic Formats}

Because many existing patient-reported outcome measures (PROMs) were developed and validated on paper, care is needed when migrating them to electronic formats to ensure that the original measurement properties of the measure are unchanged, and that the electronic format is usable in the target group of respondents [16]. Best practice for VAS migration is to present it as a horizontal line with both the item stem and its response scale visible on a single screen, including anchor text (Fig. 1b) and typically with no numbers presented at the anchor positions $[17,18]$. If the screen size permits, anchor text should be located before and after the measurement line. If screen space does not allow this, the anchor text can appear above or below the horizontal line but should include an indicator (such as a short vertical line [Fig. 1a] or arrow [Fig. 1b]) to inform the respondent to which location the text corresponds. [17].

To increase the available screen size, it may be possible to display the screen in landscape orientation, although users find automated switching in screen orientation within an assessment inconvenient [18] and some instrument owners may request additional testing (cognitive interview/usability assessment) if a change in screen orientation is introduced. The proximity to the edge of the screen of the start and end of the VAS line should enable easy selection with a finger or stylus.

In some representations, the scale appears with short vertical bars at the ends, indicating the ends of the scale. In general, a VAS presented on a mobile device will be shorter than the typical $10 \mathrm{~cm}$ pVAS, but as noted, the eVAS should span sufficient pixels to return a numeric value between 0 and 100 with all integer values possible. eVAS line width and marker thickness should be sufficient for clear visibility and fine position selection.

Many variants of the standard VAS (as described above) exist, including the incorporation of numbers at the anchor points, a numeric display to indicate the value associated with the point on the scale selected (electronic implementations), additional scale gradations, anchor descriptors associated with points on the scale other than the endpoints, and vertical orientation. The use of numbers at the anchor points of an eVAS is not recommended unless the original pVAS also displays a number along with anchor text at each end of the scale. Presentation of a numeric value associated with the point on the line selected is not recommended when migrating a VAS from paper to electronic format. The addition of a numeric indicator changes the measurement properties of the scale from a purely visual representation to a combination of a VAS and a 101-point numeric rating scale. The properties of such changes are unknown.

Although the eVAS is now commonplace, despite current published evidence of comparability between PROM administration formats that include VAS amongst other response scale types [19-21], regulators and researchers continue to question the comparability of eVAS and pVAS specifically, and $\mathrm{ePRO}$ versions with shorter lengths than the $10 \mathrm{~cm}$ pVAS leading to the need for a focussed publication on that response type specifically.

The purpose of this review was to assess whether there is sufficient evidence in the published literature to claim that eVASs are comparable to pVASs and to determine whether eVAS implementation and its length might affect PROM measurement properties.

\section{Methods}

We performed a literature search for studies evaluating the eVAS compared to the pVAS. The search was conducted using the OneSearch library database provided by Nottingham Trent University (Nottingham, UK) [22], and used the following search terms: "visual analogue scale" and "equivalence" or "validation." This list of articles was supplemented by additional published equivalence studies in which eVAS comparisons could be isolated that were referenced in published meta-analyses investigating measurement equivalence of electronic and paper PROMs [20,21] or elsewhere.

Publications identified by the search were inspected. Articles were excluded from the review if they omitted reporting 
conclusions or data in relation to the comparability of pVAS and eVAS formats, or if the eVAS implementation was seen to significantly depart from best practice recommendations defined by the Critical Path Institute's ePRO Consortium [17].

The following information (when available) was catalogued from each article: participant characteristics including disease indication and age range, sample size, eVAS and pVAS length, and PROMs studied. In one study [23], the length of eVAS was estimated from the photograph of the device displaying the eVAS presented in the publication and the known dimensions of the device. Qualitative author conclusions from each evaluation were synthesised and, where reported, quantitative measures of equivalence between the pVAS and the eVAS were recorded and summarised.

\section{Results}

Our literature search yielded a total of 26 studies. These were published between 1997 and 2018 and reported comparisons of paper and electronic formats using the VAS to measure aspects of health. Two studies were subsequently excluded based on the previously defined criteria. The first provided usability assessment of the two formats but did not assess measurement equivalence [24]. The second implemented the eVAS in an unconventional way (the marker was a large ball that could be positioned along a wide horizontal strip) [25] and was excluded as this departed considerably from best practice guidelines for electronic implementation [17]. While the authors of this study, exploring the use of an eVAS to measure pain, concluded there were no clinically relevant differences between the measures recorded on all formats studied (paper, laptop, and smartphone), they did report statistically significant differences in mean pain scores between the smartphone implementation and both paper and tablet VAS implementations (mean difference between eVAS (smartphone) and pVAS: $1.93 \mathrm{~mm} \pm 0.46 \mathrm{~mm}$ ). This bias may be a direct result of the VAS presentation used which may potentially be associated with more difficulties in accurate score positioning when used on the smaller smartphone display format. This underlines the importance of implementing the eVAS using ePRO design best practice as described above.

The 24 studies included in our evaluation $[1-4,23$, 26-44] are summarised in Table 1.

\section{Populations Studied}

Eight studies (33\%) were conducted in general population volunteers; the remainder included people diagnosed with rheumatoid arthritis $(5 / 24,21 \%)$, chronic pain $(3 / 24,12.5 \%)$, and single studies in people diagnosed with panic disorder, osteoarthritis of the knee, haemodialysis, and non-small cell lung cancer. Three further studies examined multiple populations: rheumatoid arthritis and psoriatic arthritis [30]; multiple sclerosis and general population volunteers [34]; and rheumatoid arthritis and ankylosing spondylitis [40]. One study did not report the participant population studied [33].

One study was conducted in 8- to 10-year-olds [35], and the remaining studies included adults up to 86 years old. All studies were crossover comparisons of paper to at least one form of electronic data collection. Studies varied in size from 12 to 355 participants (median: 43 participants).

\section{Constructs Measured}

VAS items included measures of pain, fatigue, global health, appetite, anxiety, osteoarthritis symptoms, activities of daily living, and alcohol effects. Most studies examined more than one construct, and therefore reported multiple VAS comparisons.

\section{Electronic Implementations Studied}

Electronic formats included: personal digital assistant (PDA) $(n=9)$, personal computer (PC) $(n=9)$, tablet $(n=3)$, smartphone (SP) $(n=2)$, feature phone (FP) (a phone with a small, simple display without touchscreen capabilities, $n=2)$, and smartwatch (SW) $(n=1)$ (Fig. 2a), with 2 studies including two electronic formats in addition to paper. One study described the hardware used to display the eVAS as a handheld computer, which we assumed to be a PC due to the year of the article and length of the eVAS [44]. eVAS length was not reported for 7 studies, and where reported ranged from $21 \mathrm{~mm}$ on a feature phone screen [37] to $200 \mathrm{~mm}$ on a PC implementation $[4,40]$.

The most common eVAS lengths studied ranged from 40 to $59.9 \mathrm{~mm}(n=8$, Fig. $2 \mathrm{~b})$, corresponding with typical smartphone and PDA formats.

\section{Author Conclusions}

Authors of 23 of the 24 studies $(96 \%)$ concluded that the eVAS and pVAS administrations were comparable. One study (4\%), assessing appetite amongst haemodialysis patients using three VAS scales to assess hunger, desire to eat, and fullness [44], concluded that both pVAS and eVAS administrations were suitable to use but were not equivalent and should not be used interchangeably. In this study, the correlations between paper and electronic formats were moderate to strong $(0.572,0.649$, and 0.770 , Table 1$)$ but in all cases there was a bias towards lower scores on the eVAS. While it is not possible to examine whether the implementation of this study followed electronic patient-reported outcome (ePRO) design best practices, the authors reported that 


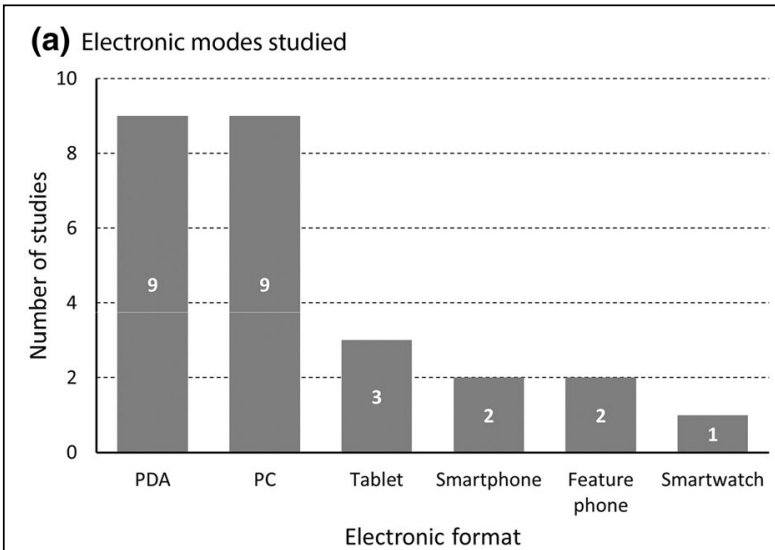

(b) Length of eVAS studied

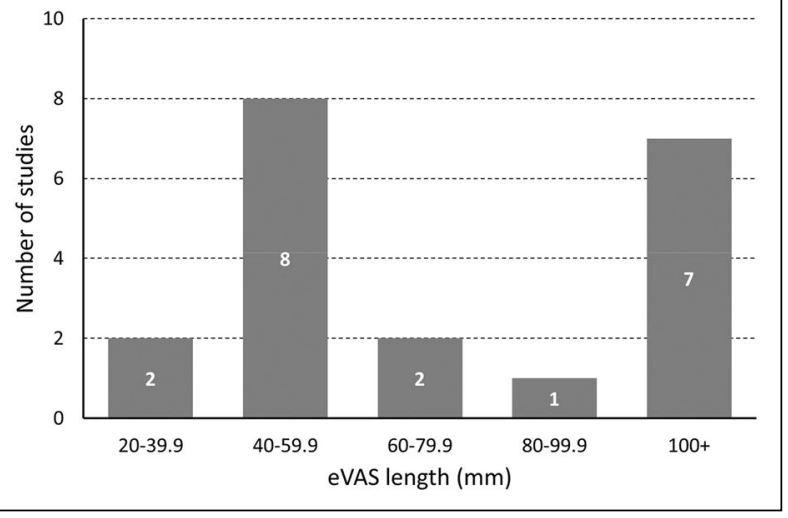

Fig. 2 Summary of eVAS implementations. a Two studies included two different electronic formats. b Seven studies did not report (or enable estimation of) eVAS length

$25 \%$ of participants indicated they would not be happy to use the electronic system again, with one usability issue being the quality of visual text displayed.

Two studies (8\%) reported trends towards higher scores on eVAS vs. pVAS [1,2], and five studies (21\%) reported the opposite finding towards lower scores on eVAS [4, 28, 35, 39, 44]. Two studies (8\%, Apple Newton and Palm PDA device) indicated eVAS scores may be lower than pVAS scores at the scale ends [36, 38]. A later study (using a Dell Pocket PC PDA device) reported no scale-end effects [27].

Authors of all articles concluded that differences between eVAS and pVAS were not clinically relevant, although in five articles (21\%) they suggested that paper and electronic forms should not be used interchangeably $[35,36,38,39$, 44].

\section{Quantitative Evaluations}

Seventeen studies $(71 \%)$ reported a measure of statistical association or correlation between eVAS and pVAS scores, with the remaining seven studies not reporting measures of association. Of the 10 studies reporting a measure of

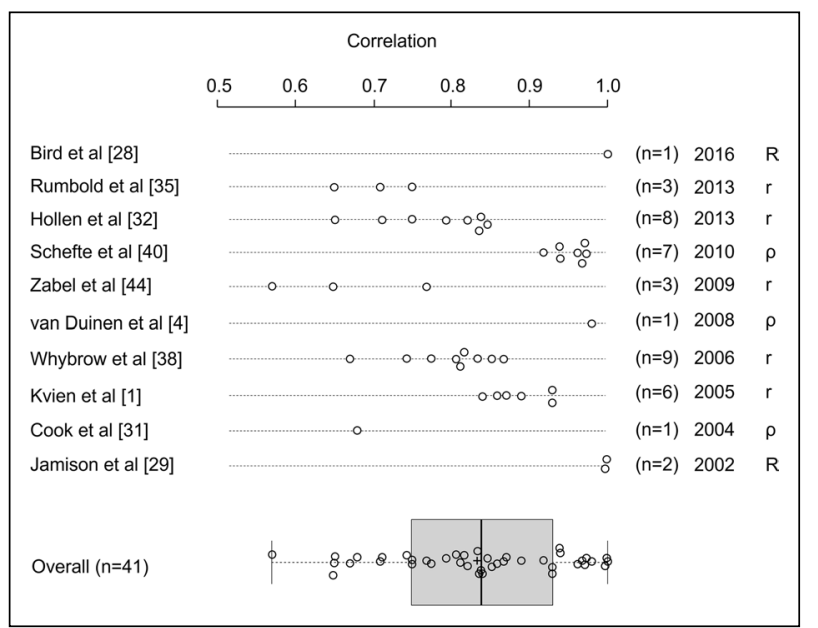

Fig. 3 Summary of correlation analyses comparing eVAS and pVAS scores $(n=41) . r$ Pearson's $r, R^{2}$ coefficient of determination, $\rho$ spearman's rho. $R^{2}$ values presented as $R$ values in this figure. Box plot description: box $=$ interquartile range; box divider $=$ median; "+"= mean; start and end of whisker lines: minimum and maximum values, respectively

correlation, Pearson's $r(r)$, coefficient of determination $\left(R^{2}\right)$ or Spearman's rho $(\rho)$ values ranged from 0.57 to 0.99 , with $85.4 \%$ of correlations exceeding 0.7 . Authors reported moderate correlations ( 0.5 to 0.7$)$ in at least 1 VAS comparison in 5/10 studies (50\%), representing 6/41 (14.6\%) reported correlations; and authors reported strong correlations $(>0.7)$ in some or all comparisons in $9 / 10$ studies (90\%), representing 35/41 (85.4\%) reported correlations (Table 1; Fig. 3).

More appropriate measures of association between pVAS and eVAS include the intraclass correlation coefficient (ICC), reported by nine studies (including two studies reporting both $r / \rho$ values and ICCs). ICC values exceeded 0.7 for all comparisons in $7 / 9(77.8 \%)$ studies and for $35 / 37$ (94.6\%) individual comparisons reported. In one study examining the equivalence of PDA and paper VAS administration using nine VAS items in people living with nonsmall cell lung cancer, one VAS item assessing haemoptysis achieved an ICC of 0.645 , with the other eight VAS items associated with ICC values above 0.7 (0.711 to 0.893) [32]. A second study in people living with rheumatoid arthritis reported ICCs for paper vs electronic administration of 0.63 , 0.841 , and 0.857 for fatigue, pain, and patient global assessment, respectively [42]. Across the 37 reported ICC values, the overall mean [SD] ICC was 0.869 [SD $=0.086$ ], with lower and upper quartiles of 0.833 to 0.940 , respectively (Fig. 4).

Considering the ICCs comparing pVAS to eVAS for measures of pain $(n=13)$ and patient global assessment $(n=9)$ separately, means [SD] of reported values were 0.901 $[\mathrm{SD}=0.048]$ and $0.871[\mathrm{SD}=0.069]$, respectively, with distributions represented in Fig. 4. Reported correlations 


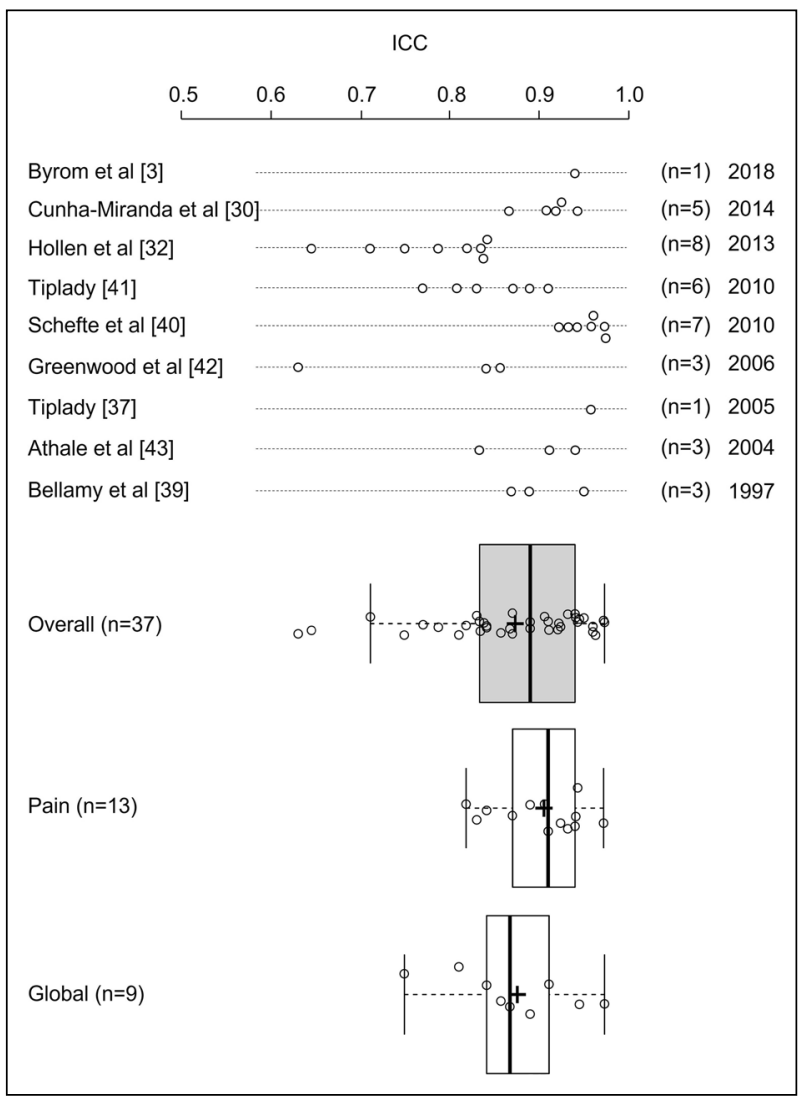

Fig. 4 Summary of ICC analyses comparing eVAS and pVAS scores $(n=37)$. Box plot description: box $=$ interquartile range; box divide $r=$ median; " $+"=$ mean; start and end of whisker lines: minimum and maximum values, respectively

between pVAS and eVAS appeared consistent independent of the age of publication (Figs. 3 and 4), suggesting that improvements in technology and its familiarity do not appear to impact the measurement comparability between formats.

\section{Discussion}

No clinically relevant difference between pVAS and eVAS was reported by authors of studies identified for inclusion within this literature review. Some scale-end effects were reported in the studies using an Apple Newton and a Palm Pilot system for data collection. These are relatively old technologies, and the design of the device may have led to this effect. While some variability in association measures was observed, the consolidated evidence is broadly supportive that pVAS and eVAS are associated with comparable measurement properties.

Current ePRO implementations are typically performed using smartphone and tablet devices. While our review included only 3 studies using these device types [3, 28, 34], these were amongst the strongest associations reported. Of the two reporting quantitative comparisons, Byrom et al. [3] reported an ICC of 0.94 (95\% confidence interval: 0.93-0.96) which included comparison of pVAS to eVAS on both provisioned smartphone and tablet devices and bringyour-own-device with varying device sizes and screen resolutions; and Bird et al. [28] reported an $R^{2}$ value of 0.9998 .

In addition, based on the publications reviewed, the length of the eVAS does not appear to affect its measurement properties, even for very short VAS lengths.

Encouragingly, the ICC values reported in our evaluation are broadly in line with other evaluations of comparability of PROM formats. This provides some face validity to the sample of studies included. The range of ICCs we report (0.63-0.96) is broadly comparable with the ranges of correlations reported by Muehlhausen et al. [20] and Gwaltney et al. [21] in their meta-analyses of paper and electronic PROMs (ranges: $0.65-0.99$ and $0.67-0.98$, respectively), although these formal meta-analyses did not distinguish individual response scale types.

Researchers should note, however, that best practices for ePRO design should be implemented when applying the VAS on an electronic medium. These are well described in the output of the ePRO Consortium [17], Oxford University Innovation [45], and industry textbooks [18] and summarised for completeness in Table 2.

Recent review articles $[8,15]$ suggest superiority of the numeric rating scale (NRS) over the VAS in adult pain measures because it was found easier to administer and score, and had both higher respondent acceptability and better psychometric properties. Electronic solutions mitigate the administration and scoring challenges associated with paper implementation of the VAS, but respondent acceptability and psychometric properties remain important considerations when considering the use of the VAS. These review articles also suggest the VAS to be more difficult for certain respondent populations to understand. While we believe this is likely, more evidence is needed to substantiate this assertion. However, while electronic tools simplify the implementation of the VAS, concerns over comprehension is one reason why new instrument developers typically select other measurement scales as opposed to the VAS.

\section{Limitations of this Research}

This literature review was not intended to be a comprehensive review of evidence regarding the comparison of eVAS with pVAS. Rather, it was designed to address whether there is sufficient evidence available to claim that pVASs are comparable to eVASs and to assess whether or not the length of the eVAS influences its measurement properties. While a modest number of studies $(n=17)$ provided a quantitative comparison of pVAS and eVAS, a formal meta-analysis was not possible due to the limitations in statistical reporting in 
Table 2 Best practice for eVAS display implementation [17]

\begin{tabular}{|c|c|}
\hline Item & Description \\
\hline \multirow[t]{2}{*}{ Orientation } & Present in a horizontal not vertical format \\
\hline & Avoid switching between portrait and landscape orientations within a measure \\
\hline Single item per page & Display the full item stem and response scale together on a single screen \\
\hline Anchor text & $\begin{array}{l}\text { If screen size is sufficient, present anchor text (verbal descriptions of the meaning of the ends of the } \\
\text { scales) horizontally before and after the measurement line. Where this is not optimal based on screen } \\
\text { size, place anchor text under the start and end of the VAS line, and use sentence wrapping and con- } \\
\text { sider arrows to make it clear that the anchors refer to the very start and end of the scale }\end{array}$ \\
\hline \multirow[t]{5}{*}{ Measurement attributes } & $\begin{array}{l}\text { The scale marker should be fine enough to enable precise location, but distinct enough to be clearly } \\
\text { visible }\end{array}$ \\
\hline & Enable both tapping and sliding to select/adjust the marker location on the line \\
\hline & $\begin{array}{l}\text { Ensure sufficient space between the edge of the screen display and the start/end of the VAS to make it } \\
\text { possible to select the very ends of the scale using a finger tap }\end{array}$ \\
\hline & $\begin{array}{l}\text { The eVAS should return an integer value from } 0 \text { to } 100 \text {. The scale must be composed of a sufficient } \\
\text { number of pixels to enable any integer value in the } 0 \text { to } 100 \text { range to be selected. Each integer value } \\
\text { should be associated with the same number of pixels on the measurement line }\end{array}$ \\
\hline & $\begin{array}{l}\text { The eVAS should not present numbers at the ends of the scale, or visually report the numeric rating } \\
\text { associated with the marked point on the scale to the respondent }\end{array}$ \\
\hline
\end{tabular}

the majority of the published studies included. For example, only 1 of the 9 studies reporting ICCs also reported ICC confidence intervals. [3]

Seven articles (29\%) did not report eVAS length. Despite this, the remaining articles reported comparisons of the $100 \mathrm{~mm}$ pVAS to eVAS lengths ranging from 21 to $200 \mathrm{~mm}$. It would be helpful to ensure that VAS lengths are reported in future studies comparing the measurement properties of eVAS and pVAS scales.

Twelve articles (50\%) were at least 10 years old and only 5 articles $(21 \%)$ were published in the last 5 years. Although screen resolutions have improved substantially, there is no reason to believe that the eVAS measurements from older devices are not comparable to those collected using more modern devices. However, as discussed above, the recessing of the screen within the hardware casing of the Apple Newton and Palm PDA devices may have contributed to the scale-end effects reported using those devices. In addition, only 5 studies investigated electronic administration of the VAS on a smartphone, a tablet, or a smartwatch. Considering the recent improvements in electronic data collection methods and technologies for clinical trials, it would be helpful to review more recent literature to corroborate these findings with current technology.

This research is general and does not focus on specific therapeutic areas or populations. While one study presented findings in children aged 8 to 10 years, we found few published studies including the use of VAS by older adults, children, or people with visual impairment or other physical restrictions.

Authors did not provide detailed descriptions of the display properties of the measures migrated from paper to electronic formats. It was therefore not possible to determine whether ePRO design best practices (e.g. those reported by the ePRO Consortium [17]) were applied in each implementation. In the future, we recommend that journal editors request screenshots illustrating the format of the migrated measure in associated supplementary online materials when accepting measurement comparability studies for publication. Despite these omissions, the results of these studies show broadly acceptable measurement comparability which is likely to be greater if the variability in implementation standards is eliminated through consistent application of best practices.

Many studies reported other forms of correlation as opposed to the ICC. In demonstrating comparability, it is more important to demonstrate a $y=x$ relationship (as achieved by the ICC analysis) as opposed to a more general measure of correlation. The studies reporting ICC did not identify the type of ICC calculated, and this is important to be able to assess the adequacy of the reported analysis. In addition, test-retest reliability measures of the paper versions were not reported, making the determination of studyspecific equivalence thresholds more difficult.

\section{Recommendations for Future VAS Use}

The use of a VAS should be carefully evaluated for implementation in a clinical trial as some respondents may have difficulty understanding the scale or may be unable to use it because of visual or physical impairment.

The ePRO Consortium does not recommend the use of VASs for newly developed PROMs because of the aforementioned difficulties for some respondents and the inability to implement a VAS scale on a voice-based system (e.g. Interactive Voice Response System [IVRS]). While 
IVRS is less frequently used, in the future we may see greater adoption of voice assistants such as Amazon Alexa or Google Assistant for data collection in clinical studies.

When implementing the VAS electronically, there is sufficient evidence already published to support measurement comparability to a paper original measure if ePRO design best practices are followed.

\section{Conclusions}

While a formal meta-analysis was not possible, this review is able to help answer the question of comparability between electronic and paper formats and the relevance of VAS length. Authors of 23 of the 24 studies evaluated concluded that pVAS and eVAS implementations were equivalent, and strong correlations and ICCs $(>0.7)$ were reported for $85.4 \%$ and $94.6 \%$ of individual scale comparisons, respectively. These strong comparability findings are despite the variety of technologies studied and the inability to assess differences between implementations against the now established best practices.

While eVAS lengths studied were as short as $21 \mathrm{~mm}$ on a feature phone [37] and $24 \mathrm{~mm}$ on a smartwatch [35], it is recommended that researchers should carefully consider the ability of users to accurately select marker positions on such small scales. For example, the smartwatch evaluation reported relatively low correlations ( 0.65 to 0.75$)$ [35] compared to other studies. It is also recommended that care is taken to avoid scale-end effects (as seen with early devices such as Apple Newton and Palm Pilot) by ensuring easy access to and selection of responses at the scale ends. While modern smartphones and tablets typically have completely flat screens, care may be needed when the devices are provided with protective shells and covers.

We conclude, therefore, that there is sufficient evidence in the literature supporting the comparability of eVAS and pVAS regardless of the VAS length, participant age, or disease population. When implementing a VAS on a screen-based electronic mode, we recommend following industry best practices for faithful migration to minimise the likelihood of non-comparability to the pVAS.

\section{Author contributions}

$\mathrm{BB}$ conceived the work; all authors contributed to the review article acquisition and summary; BB visualised the data; all authors contributed to the interpretation of findings; $\mathrm{BB}, \mathrm{CE}$ and $\mathrm{SE}$ performed the majority of manuscript writing; all authors critically reviewed drafts and approved the final submitted version. The final submitted version was approved by all ePRO Consortium member firms.

\section{Funding}

Critical Path Institute is supported by the Food and Drug Administration (FDA) of the US Department of Health and Human Services (HHS) and is $54.2 \%$ funded by FDA/HHS, totaling $\$ 13,239,950$, and $45.8 \%$ percent funded by non-government source(s), totaling $\$ 11,196,634$. The contents are those of the authors and do not necessarily represent the official views of, nor an endorsement by, FDA/ HHS or the US Government. For more information, please visit FDA. gov. Support for the ePRO Consortium comes from membership fees paid by members of the ePRO Consortium (https://c-path.org/progr ams/eproc/).

\section{Declarations}

\section{Conflict of interest}

$\mathrm{BB}, \mathrm{CE}, \mathrm{SB}, \mathrm{WM}, \mathrm{JP}, \mathrm{CW}$ and $\mathrm{CH}$ are employees of companies providing patient-reported outcomes services or solutions. SE is an employee of the Critical Path Institute.

\section{Open Access}

This article is licensed under a Creative Commons Attribution 4.0 International License, which permits use, sharing, adaptation, distribution and reproduction in any medium or format, as long as you give appropriate credit to the original author(s) and the source, provide a link to the Creative Commons licence, and indicate if changes were made. The images or other third party material in this article are included in the article's Creative Commons licence, unless indicated otherwise in a credit line to the material. If material is not included in the article's Creative Commons licence and your intended use is not permitted by statutory regulation or exceeds the permitted use, you will need to obtain permission directly from the copyright holder. To view a copy of this licence, visit http://creativecommons.org/licenses/by/4.0/.

\section{References}

1. Kvien TK, Mowinckel P, Heiberg T, et al. Performance of health status measures with a pen based personal digital assistant. Ann Rheum Dis. 2005;64(10):1480-4. https://doi.org/10.1136/ard. 2004.030437.

2. Heiberg T, Kvien TK, Dale $\varnothing$, et al. Daily health status registration (patient diary) in patients with rheumatoid arthritis: a comparison between personal digital assistant and paper-pencil format. Arthritis Care Res. 2007;57(3):454-60. https://doi.org/ 10.1002/art.22613.

3. Byrom B, Doll H, Muehlhausen W, et al. Measurement equivalence of patient-reported outcome measure response scale types collected using bring your own device compared to paper and a provisioned device: results of a randomized equivalence trial. Value Health. 2018;21(5):581-9. https://doi.org/10.1016/j.jval. 2017.10.008.

4. van Duinen M, Rickelt J, Griez E. Validation of the electronic visual analogue scale of anxiety. Prog Neuro-Psychopharmacol Biol Psychiatry. 2008;32(4):1045-7. https://doi.org/10.1016/j. pnpbp.2008.02.002.

5. De Boer AGEM, Van Lanschot JJB, Stalmeier PFM, et al. Is a single-item visual analogue scale as valid, reliable and responsive as multi-item scales in measuring quality of life? Qual Life 
Res. 2004;13(2):311-20. https://doi.org/10.1023/B:QURE.00000 18499.64574.1f.

6. Petersohn S, Ramaekers BLT, Olie RH, et al. Comparison of three generic quality-of-life metrics in peripheral arterial disease patients undergoing conservative and invasive treatments. Qual Life Res. 2019;28(8):2257-79. https://doi.org/10.1007/ s11136-019-02166-0.

7. Voutilainen A, Pitkäaho T, Kvist T, Vehviläinen-Julkunen K. How to ask about patient satisfaction? The visual analogue scale is less vulnerable to confounding factors and ceiling effect than a symmetric Likert scale. J Adv Nurs. 2016;72(4):946-57. https://doi. org/10.1111/jan.12875.

8. Safikhani S, Gries KS, Trudeau JJ, et al. Response scale selection in adult pain measures: Results from a literature review. J Patient-Reported Outcomes. 2018;2:40. https://doi.org/10.1186/ s41687-018-0053-6.

9. FDA. Guidance for industry: patient-reported outcome measures: use in medical product development to support labeling claims guidance for industry. Clin Fed Regist. 2009;12:1-39.

10. Briggs M, Closs JS. A descriptive study of the use of visual analogue scales and verbal rating scales for the assessment of postoperative pain in orthopedic patients. J Pain Symptom Manage. 1999;18(6):438-46. https://doi.org/10.1016/S0885-3924(99) 00092-5.

11. Flaherty SA. Pain measurement tools for clinical practice and research. AANA J. 1996;64(2):133-40.

12. Ferraz MB, Quaresma MR, Aquino LRL, et al. Reliability of pain scales in the assessment of literate and illiterate patients with rheumatoid arthritis. J Rheumatol. 1990;17(8):1022-4.

13. Shields BJ, Palermo TM, Powers JD, et al. Predictors of a child's ability to use a visual analogue scale. Child Care Health Dev. 2003;29(4):281-90. https://doi.org/10.1046/j.1365-2214.2003. 00343.x.

14. Jensen MP, Karoly P, Braver S. The measurement of clinical pain intensity: a comparison of six methods. Pain. 1986;27(1):117-26.

15. Gries K, Berry P, Harrington M, et al. Literature review to assemble the evidence for response scales used in patient-reported outcome measures. J Patient-Rep Outcomes. 2018;2:41. https://doi. org/10.1186/s41687-018-0056-3.

16. Coons SJ, Gwaltney CJ, Hays RD, et al. Recommendations on Evidence Needed to Support Measurement Equivalence between Electronic and Paper-Based Patient-Reported Outcome (PRO) Measures: ISPOR ePRO Good Research Practices Task Force Report. Value Health. 2009;12(4):419-29.

17. Critical Path Institute ePRO Consortium. Best Practices for Electronic Implementation of Response Scales for Patient-Reported Outcome Measures. https://c-path.org/wp-content/uploads/2018/ 09/BestPractices2_Response_Scales.pdf. Accessed 22 June 2020.

18. Byrom B, Muehlhausen W. Electronic Patient-Reported Outcome Measures: An Implementation Handbook For Clinical Research. Independently published; 2018.

19. Campbell N, Ali F, Finlay AY, Salek SS. Equivalence of electronic and paper-based patient-reported outcome measures. Qual Life Res. 2015;24(8):1949-61. https://doi.org/10.1007/ s11136-015-0937-3.

20. Muehlhausen W, Doll H, Quadri N, et al. Equivalence of electronic and paper administration of patient-reported outcome measures: a systematic review and meta-analysis of studies conducted between 2007 and 2013. Health Qual Life Outcomes. 2015; 13(1). https://doi.org/10.1186/s12955-015-0362-x.

21. Gwaltney CJ, Shields AL, Shiffman S. Equivalence of electronic and paper-and-pencil administration of patient-reported outcome measures: a meta-analytic review. Value Health. 2008;11(2):32233. https://doi.org/10.1111/j.1524-4733.2007.00231.x.
22. OneSearch library database. https://ntu-primo.hosted.exlibrisgr oup.com/primo-explore/search?vid=NTU_VU10\&lang=en_US\& sortby=rank. Accessed 22 June 2020.

23. Junker U, Freynhagen R, Langler K, et al. Paper versus electronic rating scales for pain assessment: a prospective, randomised, cross-over validation study with 200 chronic pain patients. Curr Med Res Opin. 2008;24(06):1797-806.

24. Quadri N, Muehlhausen W, Donohoe PO, et al. Exploring Patient Perceptions of, and Preferences for, Pain Response Scales on Paper and Electronic Platforms. Value Health. 2012;15(7):A482.

25. Delgado DA, Lambert BS, Boutris N, et al. Validation of digital visual analog scale pain scoring with a traditional paper-based visual analog scale in adults. JAAOS Glob Res Rev. 2018;2(3): e088. https://doi.org/10.5435/jaaosglobal-d-17-00088.

26. Kreindler D, Levitt A, Woolridge N, et al. Portable mood mapping: The validity and reliability of analog scale displays for mood assessment via hand-held computer. Psychiatry Res. 2003;120(2):165-77. https://doi.org/10.1016/S0165-1781(03) 00196-3.

27. Almiron-Roig E, Green H, Virgili R, et al. Validation of a new hand-held electronic appetite rating system against the pen and paper method. Appetite. 2009;53(3):465-8. https://doi.org/10. 1016/j.appet.2009.09.014.

28. Bird M-L, Callisaya ML, Cannell J, et al. Validity, and reliability of an electronic visual analog scale for pain on a touch screen tablet in healthy older adults: a clinical trial. Interact J Med Res. 2016;5(1): e3. https://doi.org/10.2196/ijmr.4910.

29. Jamison RN, Gracely RH, Raymond SA, et al. Comparative study of electronic vs. paper VAS ratings: a randomized, crossover trial using healthy volunteers. Pain. 2002;99:341-7.

30. Cunha-Miranda L, Barcelos FM, Miguel C, et al. AB1071 the use of visual analogue scale in rheumatic disease: validation of an electronic version. Ann Rheum Dis. 2014;73(2):1155. https:// doi.org/10.1136/annrheumdis-2014-eular.5384.

31. Cook AJ, Roberts DA, Henderson MD, et al. Electronic pain questionnaires: A randomized, crossover comparison with paper questionnaires for chronic pain assessment. Pain. 2004;110(12):310-7. https://doi.org/10.1016/j.pain.2004.04.012.

32. Hollen PJ, Gralla RJ, Stewart JA, et al. Can a computerized format replace a paper form in PRO and HRQL evaluation? Psychometric testing of the computer-assisted LCSS instrument (eLCSS-QL). Support Care Cancer. 2013;21(1):165-72. https://doi.org/10.1007/ s00520-012-1507-7.

33. Reips UD, Funke F. Interval-level measurement with visual analogue scales in internet-based research: VAS generator. Behav Res Methods. 2008;40(3):699-704. https://doi.org/10.3758/BRM. 40.3.699.

34. Kos D, Raeymaekers J, Van Remoortel A, et al. Electronic visual analogue scales for pain, fatigue, anxiety and quality of life in people with multiple sclerosis using smartphone and tablet: a reliability and feasibility study. Clin Rehabil. 2017;31(9):1215-25. https://doi.org/10.1177/0269215517692641.

35. Rumbold PLS, Dodd-Reynolds CJ, Stevenson E. Agreement between paper and pen visual analogue scales and a wristwatchbased electronic appetite rating system (PRO-Diary@), for continuous monitoring of free-living subjective appetite sensations in 7-10 year old children. Appetite. 2013;69:180-5. https://doi.org/ 10.1016/j.appet.2013.06.005.

36. Stratton RJ, Stubbs RJ, Hughes D, et al. Comparison of the traditional paper visual analogue scale questionnaire with an Apple Newton electronic appetite rating system (EARS) in free living subjects feeding ad libitum. Eur J Clin Nutr. 1998;52(10):737-41. https://doi.org/10.1038/sj.ejcn.1600636.

37. Tiplady B, Cairns W, Sturdee M, et al. The use of a mobile phone to administer a cognitive task. Paper presented at Psychobiology 
Section of the British Psychological Society, Low Wood, Windermere, UK, 2005.

38. Whybrow S, Stephen JR, Stubbs RJ. The evaluation of an electronic visual analogue scale system for appetite and mood. Eur J Clin Nutr. 2006;60(4):558-60. https://doi.org/10.1038/sj.ejen. 1602342.

39. Bellamy N, Campbell J, Stevens J, et al. Validation study of a computerized version of the Western Ontario and McMaster Universities VA30 Oesteoarthritis Index. J Rheumatol. 1997;24:2413-5.

40. Schefte DB, Hetland ML. An open-source, self-explanatory touch screen in routine care: validity of filling in the Bath measures on Ankylosing Spondylitis Disease Activity Index, Function Index, the Health Assessment Questionnaire and Visual Analogue Scales in comparison with paper. Rheumatology. 2010;49(1):99-104. https://doi.org/10.1093/rheumatology/kep333.

41. Tiplady B, Goodman K, Cummings G, et al. Patient-reported outcomes in rheumatoid arthritis assessing the equivalence of electronic and paper data collection. Patient. 2010;3(4):133-43. https://doi.org/10.2165/11536850-000000000-00000.

42. Greenwood MC, Hakim AJ, Carson E, et al. Touch-screen computer systems in the rheumatology clinic offer a reliable and user-friendly means of collecting quality-of-life and outcome data from patients with rheumatoid arthritis. Rheumatology. 2006;45(1):66-71. https://doi.org/10.1093/rheumatology/kei100.

43. Athale N, Sturley A, Skoczen S, et al. A web-compatible instrument for measuring self-reported disease activity in arthritis. $\mathrm{J}$ Rheumatol. 2004;31(2):223-8.

44. Zabel R, Ash S, Bauer J, et al. Assessment of subjective appetite sensations in hemodialysis patients: agreement and feasibility between traditional paper and pen and a novel electronic appetite rating system. Appetite. 2009;52(2):525-7. https://doi.org/10. 1016/j.appet.2008.10.010.

45. Oxford University Innovation. Patient Reported Outcomes-From Paper to ePROs Good Practice Guide for Migration; 2016. https:// innovation.ox.ac.uk/wp-content/uploads/2016/05/ePRO_guide_ 2016.pdf. Accessed 22 June 2020

46. Bruce B, Fries JF. The Stanford health assessment questionnaire: dimensions and practical applications. Health Qual Life Outcomes. 2003;1:1-6. https://doi.org/10.1186/1477-7525-1-20. 